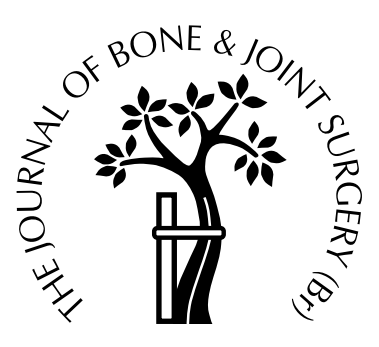

\title{
The prevention of peridural adhesions
}

\section{A COMPARATIVE LONG-TERM HISTOMORPHOMETRIC STUDY USING A BIODEGRADABLE BARRIER AND A FAT GRAFT}

\author{
Jaap J. Quist, Wouter J. A. Dhert, Björn P. Meij, Walter J. Visser, \\ F. Cumhur Oner, Herman A. W. Hazewinkel, Abraham J. Verbout \\ From the University of Utrecht, The Netherlands
}

$\mathbf{W}$ e studied peridural fibrosis in 16 dogs after laminectomies at the L2, L4 and L6 levels. They received either a free fat graft, a biodegradable mechanical barrier (polyethylene oxide (PEO)/polybutylene terephthalate (PBT) copolymer), or no treatment. The animals were killed after 4,12 , 26 and 52 weeks.

Histomorphometry showed extensive and consistent peridural fibrosis in control and PEO/PBT groups. Fat grafts produced significantly less fibrous tissue, but the presence of the fat graft in the bony defect prevented closure. Degradation of the PEO/PBT barrier resulted in the formation of more fibrous tissue.

We conclude that up to one year a free fat graft is effective in reducing the amount of peridural scarring.

J Bone Joint Surg [Br] 1998;80-B:520-6.

Received 27 May 1997; Accepted after revision 21 November 1997

Peridural fibrosis can develop after a laminectomy ${ }^{1,2}$ causing traction on the dura mater or nerve roots or both, resulting in low back or pseudoradicular pain. ${ }^{3,4}$ There may be a direct relationship between peridural fibrosis and recurring chronic pain, contributing to the failed back surgery syndrome. 'Removal of such scar tissue may reduce pain ${ }^{4}$ and a recent MRI study has suggested a relationship between peridural fibrosis and recurrent radicular pain. ${ }^{6}$

J. J. Quist, MD, Senior Resident in Orthopaedics

W. J. A. Dhert, MD, PhD, Head of Orthopaedic Research

W. J. Visser, DDS, PhD, Histopathologist

F. C. Oner, MD, Consultant Orthopaedic Surgeon

A. J. Verbout, MD, PhD, Professor of Orthopaedics and Head of Department

University Cluster of Orthopaedics, Utrecht University, University Hospital, Room G05.228, PO Box 85500, 3508 GA Utrecht, The Netherlands.

B. P. Meij, DVM, PhD, Diplomat ECVS

H. A. W. Hazewinkel, DVM, PhD, Diplomat ECVS

Department of Clinical Sciences of Companion Animals, Faculty of

Veterinary Medicine, Utrecht University, 3584 CL Utrecht, The

Netherlands.

Correspondence should be sent to Dr W. J. A. Dhert.

(C)1998 British Editorial Society of Bone and Joint Surgery

0301-620X/98/38010\$2.00
Prevention of postlaminectomy scarring has been attempted using degradable, or non-degradable, mechanical barriers, $^{7-10}$ chemical regulation of the process of scar formation, $^{11-14}$ and the prevention of local haematomas. ${ }^{11,15}$ An autogenous free fat transplant has been shown to be effective ${ }^{15-17}$ but is known to have complications such as necrosis, fibrosis and compression of the spinal cord by migration of fat into the epidural space. ${ }^{18,19}$

It has been suggested that a biodegradable polymer (polyethylene oxide (PEO)/polybutylene terephthalate (PBT) copolymer) may prevent scarring and adhesions in rats $^{20}$ and in dogs. ${ }^{21,22}$

We compared the results of a free fat graft and a PEO/ PBT barrier sheet over a period of one year using quantitative histology.

Materials and Methods

Design. In a prospective, randomised control study in 16 dogs we compared three treatments for the prevention of postlaminectomy scar formation: 1) barrier sheets made of PEO/PBT copolymer; 2) free autogenous fat grafts; and 3) no barrier sheet or a fat graft. Each animal had three laminectomies at lumbar vertebrae L2, L4 and L6. The three treatments were randomised to the three laminectomy sites to eliminate possible small differences between the three levels and to provide internal controls within each animal. The animals were studied at follow-up periods of 4 , 12,26 or 52 weeks.

PEO/PBT copolymer. Barrier sheets of PEO/PBT copolymer in a ratio of 60:40 were made by HC Implants B.V., Leiden, The Netherlands, using a solvent casting method. The resulting membrane had a dense top layer and a porous under layer, with a total thickness of approximately $280 \mu \mathrm{m}$. After casting and chloroform evaporation, the films were immersed in distilled water to rinse out salts and were then air-dried. Sheets $(50 \times 50 \times 280 \mu \mathrm{m})$ were cut from the film, vacuum-sealed and sterilised by gamma irradiation at $\geq 25 \mathrm{kGy}$. The structure of the bilayer was evaluated by SEM (Fig. 1a). During surgery, the PEO/PBT sheets were trimmed with scissors to fit the site of the defect (Fig. 1b) and placed ventral to the defect with the dense side facing the dura mater.

Experimental animals. Protocols were approved by our 


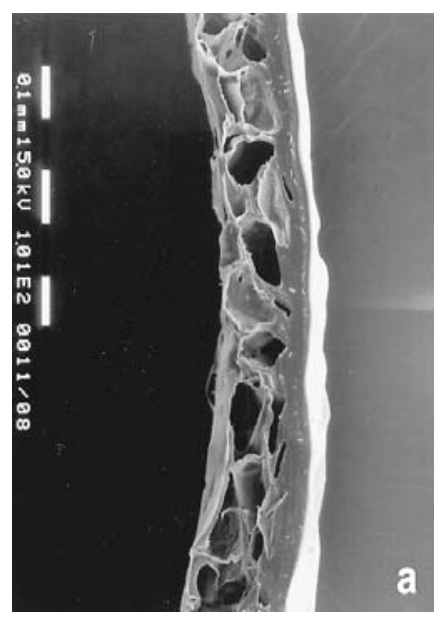

Fig. 1a

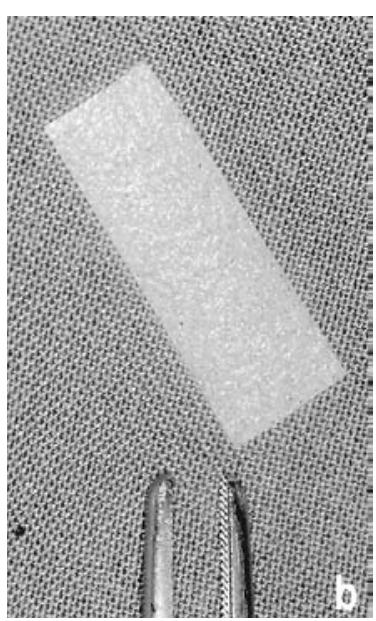

Fig. 1b
Figure 1a - Lateral SEM of a PEO/PBT barrier sheet showing porous and dense sides. Figure $1 \mathrm{~b}-$ The barrier sheet before placement in the defect.

local ethical committee. We used adult Beagle dogs of either sex, weighing 11 to $15 \mathrm{~kg}$, from a professional stockbreeder. The dogs were housed individually in indoor kennels under a normal daylight regime, were fed commercial dry, pelleted dog food and had free access to water. The animals were adapted to these conditions from two weeks before the start of the experiment and were examined by a veterinary surgeon (BPM) before operation after an overnight fast.

Operation. After intramuscular premedication with acepromazine $0.1 \mathrm{mg} / \mathrm{kg}$, methadone $1 \mathrm{mg} / \mathrm{kg}$, and atropine $0.1 \mathrm{mg} / \mathrm{kg}$, anaesthesia was induced by the intravenous administration of sodium pentothal $0.1 \mathrm{mg} / \mathrm{kg}$. The dogs were intubated and inhalation anaesthesia maintained in a semiclosed system with a mixture of halothane, $\mathrm{NO}_{2}$ and $\mathrm{O}_{2}$. Preoperative antibiotic prophylaxis was by the intravenous administration of gentamicin $3 \mathrm{mg} / \mathrm{kg}$ and lincomycin $5 \mathrm{mg} / \mathrm{kg}$. To minimise oedema of the spinal cord due to surgical trauma, dexamethasone $1 \mathrm{mg} / \mathrm{kg}$ was given intravenously before surgery.

The lumbar and lumbosacral regions were clipped and the surgical field disinfected with povidone-iodine. The laminae of lumbar vertebrae L6, L4 and L2 were successively approached through a dorsal incision as described previously. ${ }^{23}$ The lumbar fascia and supraspinous ligament were incised around each spinous process, and on the midline between each process. Elevation was most easily done from a caudal-to-cranial direction. Dorsal laminectomy began by removal of the spinous process with a rongeur; the laminae were excised with a pneumatic burr under continuous irrigation and cooling with saline. Burring stopped when the ventral cortical layer of the vertebral lamina was encountered. After incision of the interarcuate ligament, the remaining laminar cortical layer was removed with fine neurosurgical punches to minimise surgical trauma to the dura mater and spinal cord. The dura mater was exposed by removing the interarcuate ligament and the epidural fat. The laminectomy defect created in this way was about $5 \times 20 \mathrm{~mm}$ at each site.

One of the three treatment options was then applied: control, fat graft, or barrier sheet. Autogenous fat was obtained from the subcutaneous fat dorsal to the surgical site. After treatment, the multifidus lumborum muscle was replaced in its original position and the lumbar fascia was partially closed with interrupted absorbable polyglactin sutures.

Postoperative analgesia was provided by the intravenous administration of buprenorphin $0.1 \mathrm{mg} / \mathrm{kg}$ at the end of surgery and subsequently subcutaneously every eight hours for at least 24 hours. The animals were observed carefully in the postoperative period, and if additional pain relief was necessary, the administration of buprenorphin was prolonged. Postoperative antibiotic prophylaxis was by the subcutaneous administration of gentamicin $3 \mathrm{mg} / \mathrm{kg}$ and lincomycin $5 \mathrm{mg} \mathrm{kg}$ every eight hours for 24 hours. After this, amoxycillin/clavulanic acid $12 \mathrm{mg} / \mathrm{kg}$ was given orally twice daily for seven days.

At the end of follow-up, the animals were killed with a concentrated solution of pentobarbital. Cerebrospinal fluid (CSF) was collected through a puncture in the neck and samples were analysed for cytology and glucose and protein content. In addition, peripheral blood samples were analysed for glucose content.

Histological examination. All fixation and dehydration procedures were performed at room temperature. The distal spine (L1 to L7), including the intrinsic musculature, was removed en bloc and placed in buffered formaldehyde for at least three days. The L2, L4 and L6 levels were sawn and the entire laminectomy site removed without damage. These tissue blocks were again placed in buffered formaldehyde. After one week, they were sawn transversely through the middle of the laminectomy site and replaced in buffered formaldehyde for final fixation and dehydrated. The proximal half was embedded in polymethylmethacrylate (PMMA) from which sections of 5 to $10 \mu \mathrm{m}$ were cut using a specially designed hard-tissue saw. ${ }^{24}$ These were stained with basic fuchsin and methylene blue. A slice of the distal half of the tissue block was decalcified and embedded in paraffin and thin sections were cut and stained with haematoxylin and eosin.

All sections were examined by a light microscope (Olympus BX-50) to measure the tissue response to the various treatments, the fate of the laminectomy defect, and the extent and morphology of the scar tissue. The organisation of the collagen fibres was determined using polarised light.

Histomorphometry. This was performed on the non-decalcified, PMMA-embedded specimens. The full laminectomy region, with the dura mater and spinal cord, was outlined by hand on a sheet of paper using a Leitz Projection microscope. These drawings were analysed by an IBAS image analysis system (Kontron/Zeiss, Eching, Germany). 


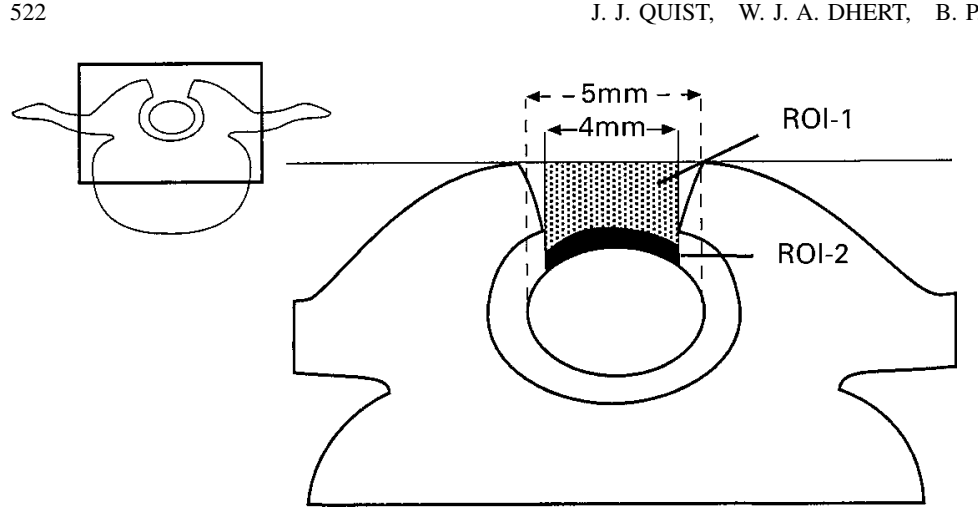

Fig. 2

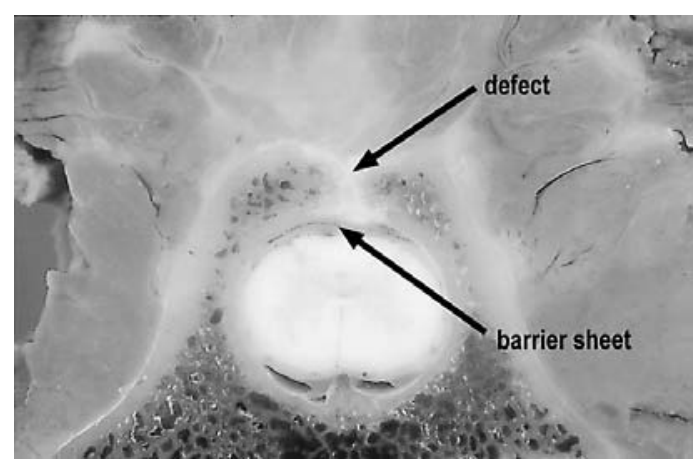

Fig. 3

Figure 2 - Diagram showing ROI-1 and ROI-2. In ROI-1, the percentage area of fibrous tissue and bone was measured and in ROI- 2 the percentage area of only fibrous tissue was measured. Figure 3 - Transverse section showing the macroscopic appearance of a defect treated with a barrier sheet. The position of the barrier sheet between the dura mater and the defect is clearly visible.

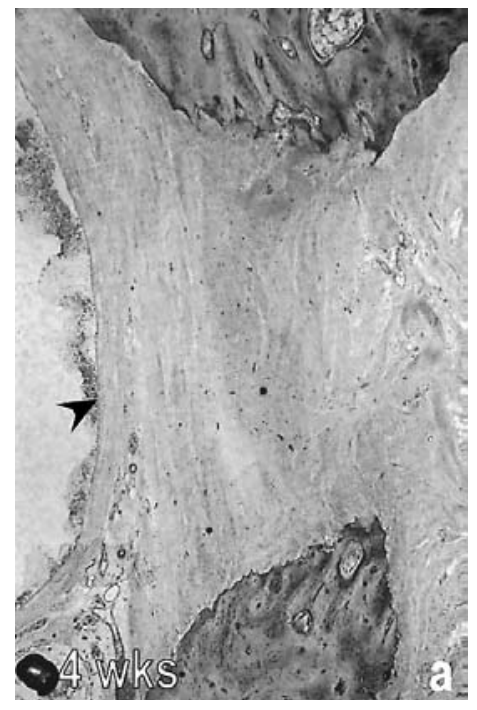

Fig. 4a

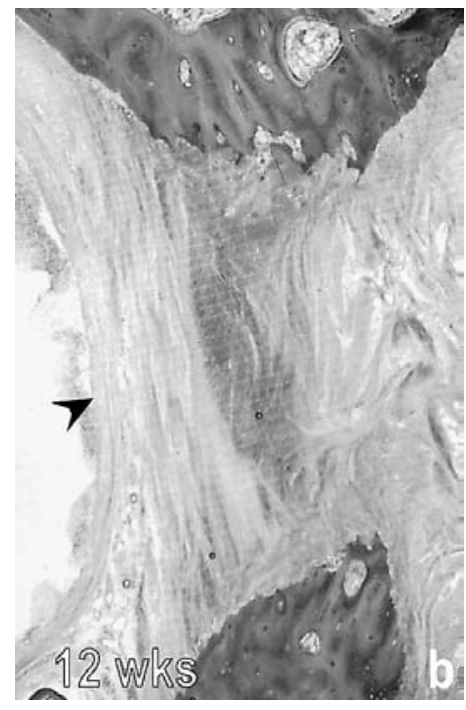

Fig. $4 \mathrm{~b}$

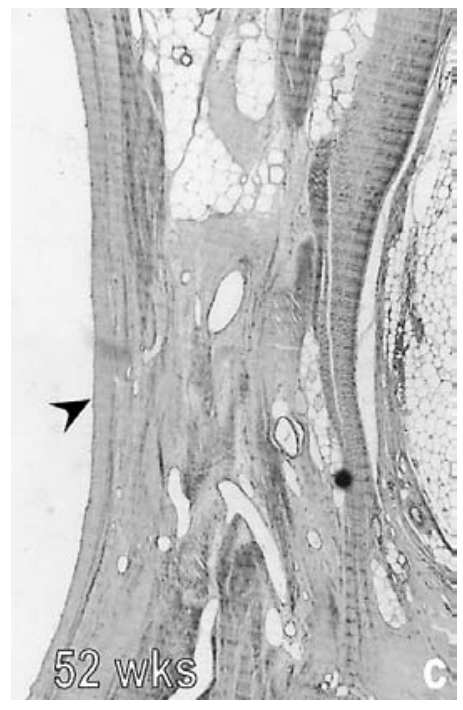

Fig. $4 \mathrm{c}$

Photomicrographs of control defects after 4 weeks (a), 12 weeks (b) and 52 weeks (c). Dense fibrous tissue has developed in the laminectomy defect and is extending towards the dura mater (arrowheads) (non-decalcified section; basic fuchsin and methylene blue $\times 32$ ).

They were then scanned with a Panasonic black and white CCD camera, type WC-CD50, digitised four times and averaged to improve the signal-to-noise ratio (frame size $768 \times 512$ pixels; 256 grey levels).

We developed a program to measure the percentage of bone and fibrous tissue in two regions of interest (ROI): ROI-1 represented an area in the laminectomy defect $500 \mu \mathrm{m}$ from the dura mater and ROI- 2 was a peridural zone of $500 \mu \mathrm{m}$ thickness (Fig. 2). ROI was determined by positioning a tangent line along the dorsal edges of the defect, perpendicular to which two outer lines were projected ventrally towards the dura mater at a distance representing $4 \mathrm{~mm}$ in the original section. These two lines were carefully positioned in the middle of the original defect and their crossing point with the dura mater was traced by hand. The projection $500 \mu \mathrm{m}$ dorsally of this contour line was calculated by computer.
For each follow-up, we analysed the differences between the three treatment groups statistically using a one-way analysis of variance (SPSS 6.0 for the Macintosh). If a significant difference $(\mathrm{p} \leq 0.05)$ was found the treatment pairs were compared by Student-Newman-Keuls testing.

\section{Results}

One animal (26-week follow-up) developed a partial paresis of both hind legs postoperatively which resolved after one week. The other 15 animals recovered without complications and could stand and walk within one day. Analysis of the CSF revealed no pathology nor did macroscopic inspection of the transverse sections through the laminectomy sites (Fig. 3).

Histological examination. In the control defects a dense fibrous tissue layer had developed to the laminectomy at all 


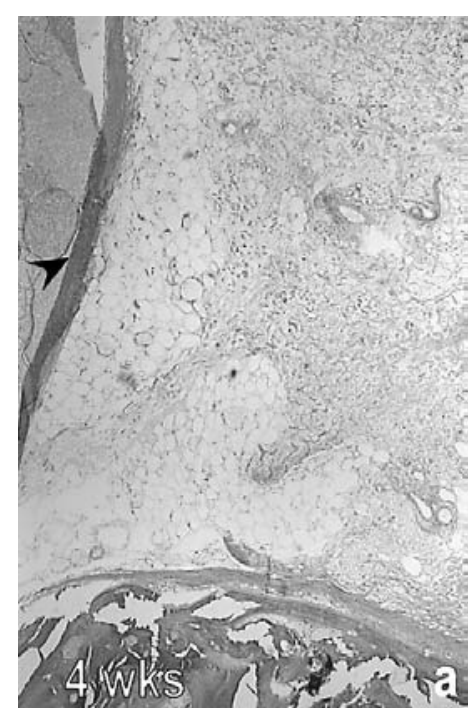

Fig. 5a

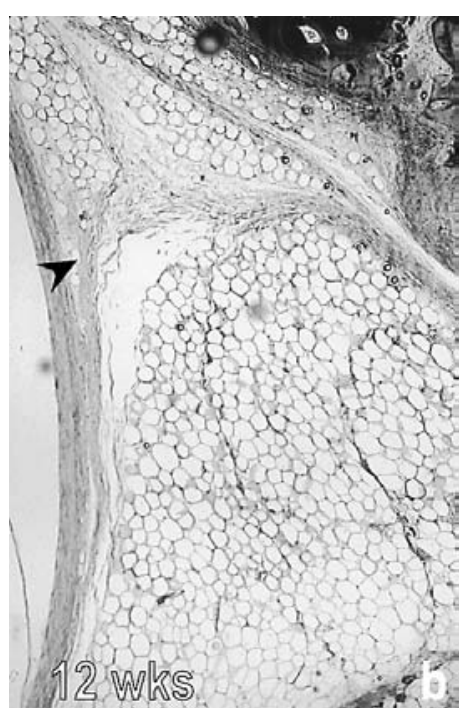

Fig. $5 b$

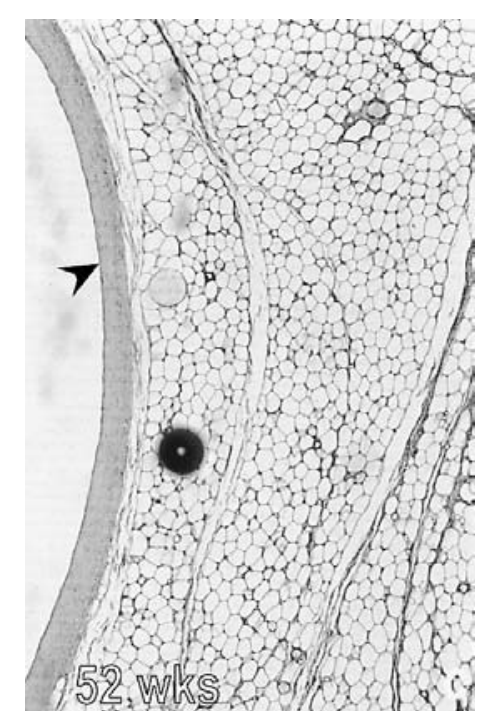

Fig. 5c

Photomicrographs of defects treated with a free fat graft. Vital, non-fibrotic fat tissue is in contact with the dura mater (a,c, arrowheads) or there is a thin fibrous tissue layer (b, arrowhead) between the fat graft and the dura mater. There is no gross degeneration or fibrosis although some strings of fibrous tissue are present in the grafts (non-decalcified section; basic fuchsin and methylene blue $\times 32$ ).

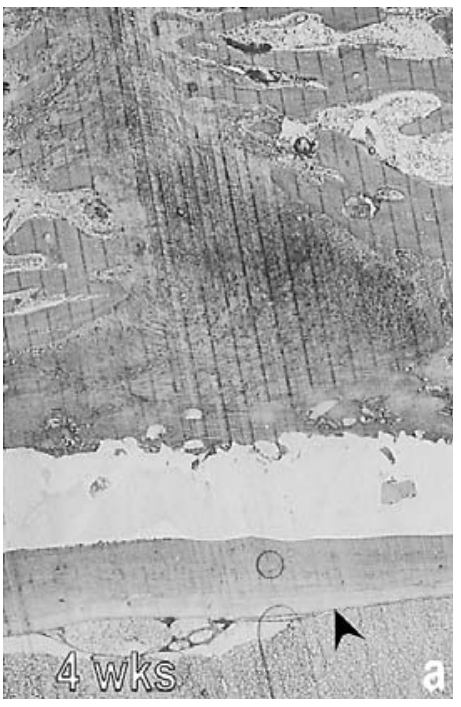

Fig. 6a

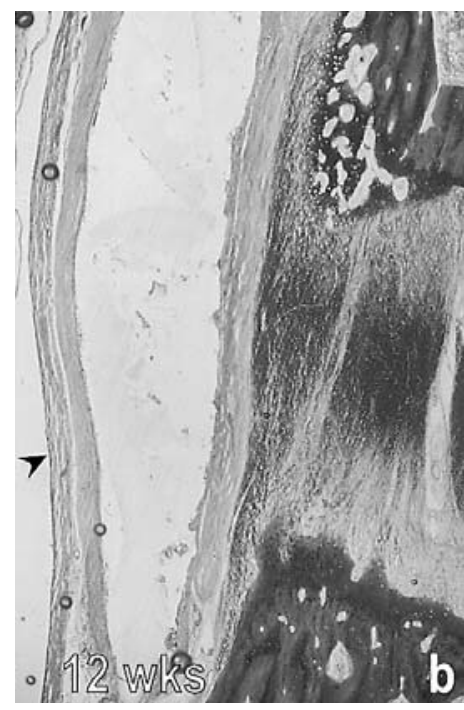

Fig. $6 \mathrm{~b}$

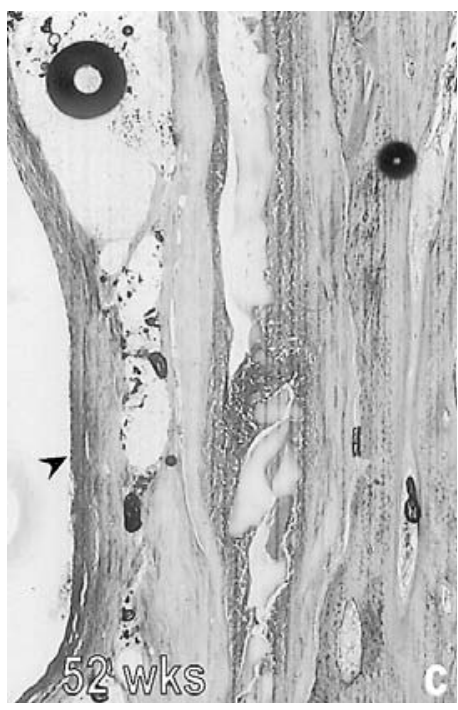

Fig. 6c

Photomicrographs of defects treated with a PEO/PBT barrier sheet. After 4 and 12 weeks (a,b) the PEO/PBT membrane is present between the dense fibrous tissue at the dorsal side and the dura mater. The membrane itself is surrounded by a thin fibrous tissue layer. After 52 weeks (c) degeneration and fragmentation of the membrane are clearly visible and fibrous tissue is present between the fragments of the PEO/PBT (arrowheads = dura mater; non-decalcified section, basic fuchsin and methylene blue $\times 32)$.

follow-up periods (Fig. 4). The collagen fibres in this tissue were predominantly parallel to the dura mater but in some sections the fibres lay in other directions (Fig. 4c). In some defects the laminectomy site had been partially closed by new bone, but this did not affect the presence of fibrous tissue dorsal to the dura mater.

Defects treated by fat graft showed non-fibrotic fat tissue close to and in contact with the dura mater (Fig. 5). Signs of degeneration were sometimes seen more dorsally. In several grafts there were strings of fibrous tissue but we could not determine whether these had already been present or were newly formed. Three of the defects (4 and 12 weeks) had a fibrous tissue layer between the graft and the edges of the lateral defect (Fig. 5a), and in two of the defects (4 and 12 weeks) we found a thin layer of fibrous tissue between the graft and the dura mater. The fat grafts could easily be detected and none of the sections showed gross degeneration or scarring.

The defects treated with the PEO/PBT barrier sheet (Fig. 6) showed a fibrous tissue layer dorsal to the dura which was between 20 and 50 cells thick. In the 4- and 12-week samples, this fibrous tissue was interrupted dorsally by the 


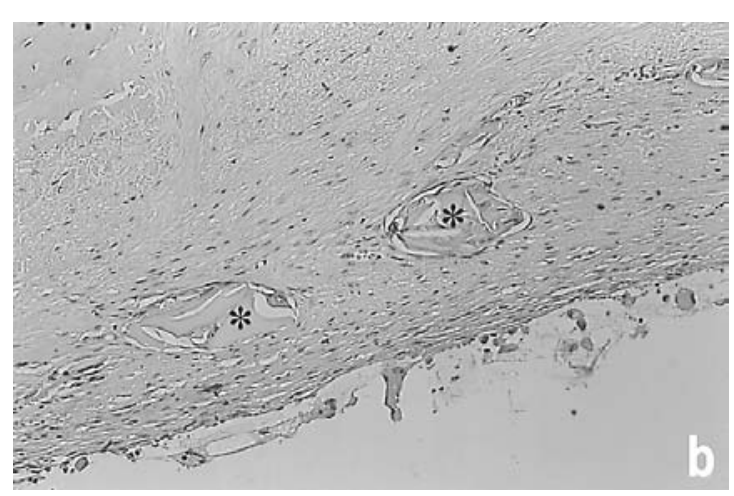

Fig. $7 b$

Photomicrographs of PEO/PBT-treated defects showing fibrous tissue next to a PEO/PBT membrane. PEO/PBT fragments (asterix) are surrounded by fibroblasts and macrophages with single intracellular fragments (arrow) or a 'foamy cytoplasm' can be seen. Figure 7a - A non-decalcified section 26 weeks after implantation (basic fuchsin and methylene blue $\times 190$ ). Figure 7b - A decalcified section after 12 weeks (haematoxylin and eosin $\times 190$ ).

Table I. Percentage of fibrous tissue in ROI-1 determined by analysis of variance and Student-Newman-Keuls testing ( $\mathrm{F}=$ probability of $\mathrm{F}$ (ANOVA))

\begin{tabular}{lllll}
\hline & \multicolumn{4}{l}{ Follow-up (wk) } \\
\cline { 2 - 5 } & $\mathbf{4}$ & $\mathbf{1 2}$ & $\mathbf{2 6}$ & $\mathbf{5 2}$ \\
& $\mathbf{F} \leq \mathbf{0 . 0 0 0 1}$ & $\mathbf{F} \leq \mathbf{0 . 0 5}$ & $\mathbf{F} \geq \mathbf{0 . 0 5}$ & $\mathbf{F} \leq \mathbf{0 . 0 5}$ \\
\hline Control - Fat & $*$ & $*$ & NS & $*$ \\
Control - PEO/PBT & NS & $*$ & NS & NS \\
PEO/PBT - Fat & $*$ & NS & NS & $*$ \\
\hline
\end{tabular}

* significant difference between groups

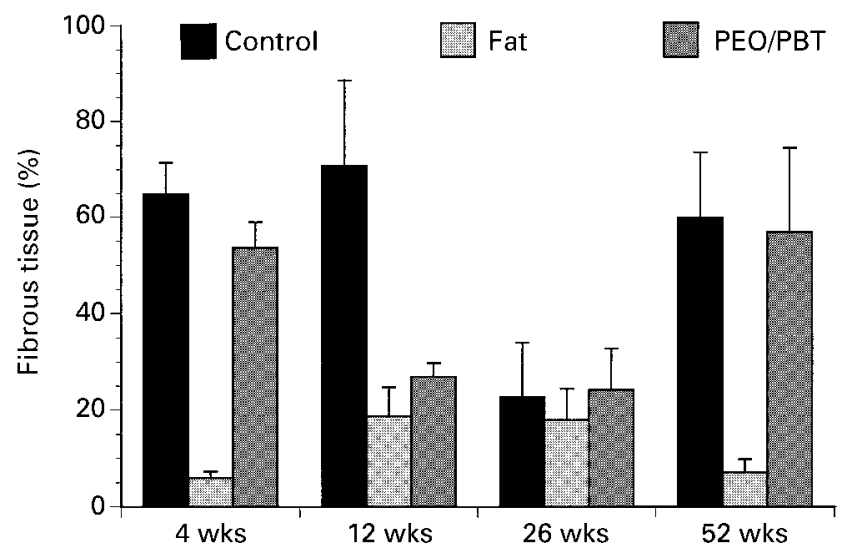

Fig. 8

The percentage of fibrous tissue in ROI-1 for the various treatments and follow-up periods.

barrier sheet. At 4 and 12 weeks the barrier sheet had itself provoked a mild fibrous tissue response; on the porous side of the sheet this was more active with macrophages and multinuclear giant cells. After 12 weeks, the first signs of degradation of the sheet were apparent as cracks, the presence of macrophages with single intracellular fragments or 'foamy' cytoplasm at the porous side (Fig. 7). Fragmentation of the sheet was visible after 26 weeks and more obvious at 52 weeks when degeneration was visibly associated with the formation of fibrous tissue.
Table II. Percentage of bone in ROI-1 determined by analysis of variance and Student-Newman-Keuls testing ( $\mathrm{F}=$ probability of $\mathrm{F}$ (ANOVA))

\begin{tabular}{lllll}
\hline & \multicolumn{4}{l}{ Follow-up $(\mathbf{w k})$} \\
\cline { 2 - 5 } & $\mathbf{4}$ & $\mathbf{1 2}$ & $\mathbf{2 6}$ & $\mathbf{5 2}$ \\
& $\mathbf{F} \leq \mathbf{0 . 0 0 5}$ & $\mathbf{F} \geq \mathbf{0 . 0 5}$ & $\mathbf{F} \geq \mathbf{0 . 0 5}$ & $\mathbf{F} \geq \mathbf{0 . 0 5}$ \\
\hline Control - Fat & $*$ & NS & NS & NS \\
Control - PEO/PBT & NS & NS & NS & NS \\
PEO/PBT - Fat & $*$ & NS & NS & NS \\
\hline
\end{tabular}

* significant difference between groups

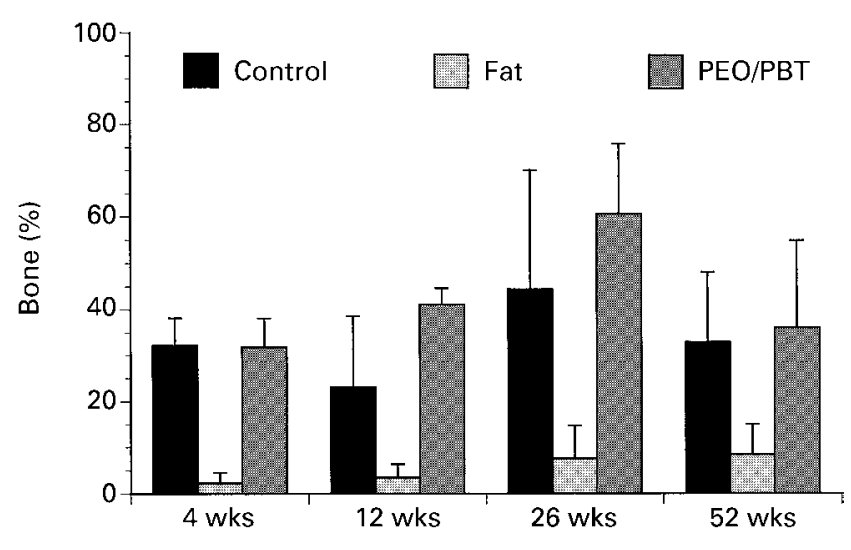

Fig. 9

The percentage of bone in ROI- 1 for the various treatments and follow-up periods.

Histomorphometry. After 4, 12 and 52 weeks, the fattreated defects in ROI-1 had significantly less fibrous tissue than the control defects, and after 4 and 52 weeks also less than the PEO/PBT-treated defects (Table I; Fig. 8). They also had a very low percentage of bone which reached a maximum after 52 weeks of $8.4 \pm 6.6 \%$ (Table II; Fig. 9). The control and PEO/PBT-treated defects had higher percentages of bone in the defect at all the follow-up periods, but bony closure was not consistent for all control and PEO/PBT defects. There was a high variation and only at 
Table III. Percentage of fibrous tissue in ROI-2 determined by analysis of variance and Student-Newman-Keuls testing $(\mathrm{F}=$ probability of $\mathrm{F}$ (ANOVA))

\begin{tabular}{lllll}
\hline & \multicolumn{4}{l}{ Follow-up (wk) } \\
\cline { 2 - 5 } & $\mathbf{4}$ & $\mathbf{1 2}$ & $\mathbf{2 6}$ & $\mathbf{5 2}$ \\
& $\mathbf{F} \leq \mathbf{0 . 0 0 0 5}$ & $\mathbf{F} \leq \mathbf{0 . 0 5}$ & $\mathbf{F} \leq \mathbf{0 . 0 0 0 5}$ & $\mathbf{F}$ \\
& & & & $\leq \mathbf{0 . 0 0 1}$ \\
\hline Control - Fat & $*$ & $*$ & $*$ & $*$ \\
Control - PEO/PBT & $*$ & NS & $*$ & NS \\
PEO/PBT - Fat & $*$ & NS & $*$ & $*$ \\
\hline
\end{tabular}

* significant difference between groups

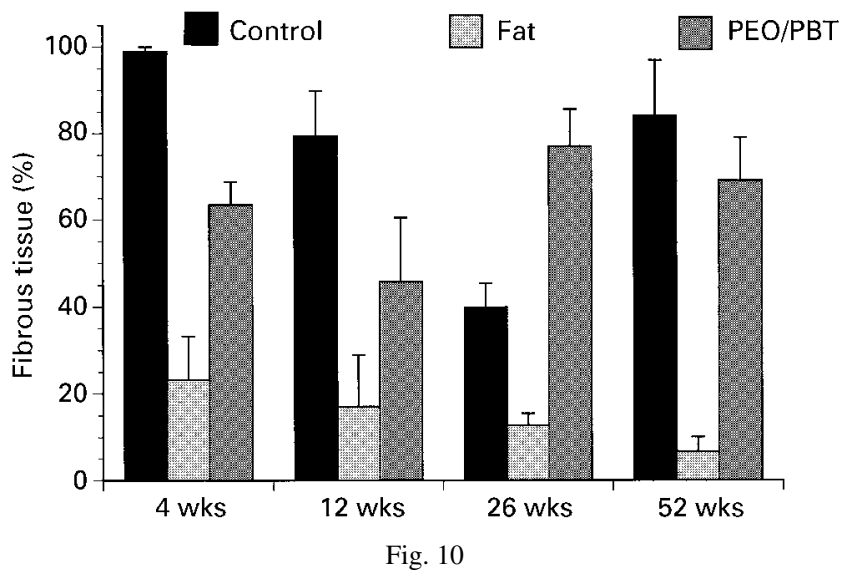

The percentage of fibrous tissue in ROI- 2 for the various treatments and follow-up periods.

four weeks were there significant differences between the fat and control or the fat and $\mathrm{PEO} / \mathrm{PBT}$ groups.

In ROI-2 there was more fibrous tissue in the control group compared with the fat-treated group, and for the PEO/PBT group more fibrous tissue than in the fat group after 4, 26 and 52 weeks (Table III; Fig. 10).

\section{Discussion}

Our findings clearly show that free fat grafts effectively prevent peridural fibrosis. Previous studies have reported problematic or inconsistent results with fat grafts. $7,15,18,19,25$ Weisz and $\mathrm{Gal}^{17}$ reported in a study on patients that fat grafts were effective and had a long survival, but most studies refer to clinical case reports rather than randomised, prospective studies. In some sections we found signs of degeneration of the fat graft on its dorsal side or the presence of fibrous tissue at the edges of the graft, but never necrosis of the graft.

It is likely that our good results are related to the surgical procedures. We used a relatively large free fat graft which was removed with great care and placed immediately into the defect. Our defects were of standard size $(5 \times 20 \mathrm{~mm})$ whereas it is sometimes necessary to have a larger defect to allow better access to the vertebral canal. In addition, we were able to maintain very strict haemostasis since no additional surgery was performed. In all defects treated with a fat graft, we found that the bone defects remained open.

Since the PEO/PBT barrier sheet is relatively thin, we did not expect it to prevent the formation of fibrous tissue. There are no long-term data regarding the degradation of PEO/PBT barrier sheets. In our study, phagocytosis of small fragments of the material or its degradation products would seem to be important, but other degradation mechanisms cannot be excluded and the experimental protocol did not allow for measurement of the local $\mathrm{pH}$. Degradation was first seen after 12 weeks and continued at 26 and 52 weeks and fibrous tissue developed, indicating that the barrier sheet is not effective in the long term. Our results also emphasise that, in the study of degradable barriers, it is essential to extend follow-up until the process of degeneration is complete. Despite careful surgery, the control group consistently developed a dense fibrous tissue layer.

Our findings show that degradation of the PEO/PBT barrier resulted in the formation of more fibrous tissue. We conclude that for up to one year a free fat graft is more effective in preventing peridural scarring.

Although none of the authors have received or will receive benefits for personal or professional use from a commercial party related directly or indirectly to the subject of this article, benefits have been or will be received but are directed solely to a research fund, educational institution, or other non-profit institution with which one or more of the authors is associated.

\section{References}

1. Wiesel SW. The multiply operated lumbar spine. AAOS Instructional Course Lectures 1985;34:68-77.

2. La Rocca H, Macnab I. The laminectomy membrane: studies in its evolution, characteristics, effects and prophylaxis in dogs. $J$ Bone Joint Surg [Br] 1974;56-B:545-50.

3. Macnab I. Backache. Baltimore: Williams and Wilkins, 1990:330.

4. Benoist M, Ficat C, Baraf P, Cauchoix J. Postoperative lumbar epiduro-arachnoiditis: diagnosis and therapeutic aspects. Spine 1980; 5:432-6.

5. Robertson JT. Role of peridural fibrosis in the failed back: a review. Eur Spine J 1996;5(Suppl 1):2-6.

6. Petrie JL, Ross JS. Use of Adcon-L to inhibit postoperative peridural fibrosis and related symptoms following lumbar disc surgery: a preliminary report. Eur Spine J 1996;5(Suppl 1):10-7.

7. Langenskiold A, Kiviluoto O. Prevention of epidural scar formation after operations on the lumbar spine by means of free fat transplants: a preliminary report. Clin Orthop 1976;115:92-5.

8. Barbera J, Gonzalez J, Esquerdo J, Broseta J, Bacia-Salorio JL. Prophylaxis of the laminectomy membrane: an experimental study in dogs. J Neurosurg 1978;49:419-24.

9. Lawson KJ, Malycky JL, Berry JL, Steffee AD. Lamina repair and replacement to control laminectomy membrane formation in dogs. Spine 1991;16(6 Suppl):222-6.

10. Lee CK, Alexander H. Prevention of postlaminectomy scar formation. Spine 1984;9:305-12.

11. Abitbol JJ, Lincoln TL, Lind BI, et al. Preventing postlaminectomy adhesion: a new experimental model. Spine 1994;19:1809-14.

12. He Y, Revel M, Loty B. A quantitative model of post-laminectomy scar formation: effects of a nonsteroidal anti-inflammatory drug. Spine 1995;20:557-63; discussion 79-80.

13. Hinton JL Jr, Warejcka DJ, Mei Y, et al. Inhibition of epidural scar formation after lumbar laminectomy in the rat. Spine 1995;20:564-70; discussion 79-80.

14. Songer MN, Rauschning W, Carson EW, Pandit SM. Analysis of peridural scar formation and its prevention after lumbar lamonotomy and discectomy in dogs. Spine 1995;20:571-80.

15. Jacobs RR, McClain O, Neff J. Control of postlaminectomy scar formation: an experimental and clinical study. Spine 1980;5:223-9. 
16. Gill GG, Scheck M, Kelley ET, Rodrigo JJ. Pedicle fat grafts for the prevention of scar in low-back surgery: a preliminary report on the first 92 cases. Spine 1985;10:662-7.

17. Weisz GM, Gal A. Long-term survival of a free fat graft in the spinal canal: a 40-month postlaminectomy case report. Clin Orthop 1986; 205:204-6.

18. Keller JT, Dunsker SB, McWhorter JM, et al. The fate of autogenous grafts to the spinal dura: an experimental study. J Neurosurg 1978;49:412-8.

19. Prusick VR, Lint DS, Bruder WJ. Cauda equina syndrome as a complication of free epidural fat-grafting: a report of two cases and a review of the literature. J Bone Joint Surg [Am] 1988;70-A:1256-8.

20. Bakkum EA, Trimbos JB, Dalmeijer RAJ, Van Blitterswiijk CA. Preventing postoperative intraperitoneal adhesion formation with polyactive, a degradable copolymer acting as a barrier. J Mat Sci: Mat in Med 1995;6:41-5.
21. Cook SD, Prewett AB, Dalton JE, Whitecloud TS 3rd. Reduction in perineural scar formation after laminectomy with Polyactive membrane sheets. Spine 1994;19:1815-25.

22. Quist JJ, Dhert WJA, Visser W, et al. A histological study on polyactive for the prevention of peridural adhesions after spinal surgery: an experimental study in dogs with a 3 months follow-up. $J$ Mat Sci: Mat in Med 1995;6:731-8.

23. Piermattei DL. An atlas of surgical approaches to the bones and joints of the dog and cat. 3rd ed. Philadelphia: W.B. Saunders Company, 1993:70-5.

24. Klein CP, Sauren YM, Modderman WE, van der Waerden JP. A new saw technique improves preparation of bone sections for light and electron microscopy. J Appl Biomater 1994;5:369-73.

25. Robertson JT, Meric AL, Dohan FC, et al. The reduction of postlaminectomy peridural fibrosis in rabbits by a carbohydrate polymer. J Neurosurg 1993;79:89-95. 